\title{
Changes in the Saliva Cortisol Concentration and Blood Pressure of Patients with High Blood Pressure and Diabetes After Participating in Agro-healing Activities
}

\author{
Hye Sook Jang1, Eunha Yoo ${ }^{1}$, Sun-Jin Jeong ${ }^{1}$, Jae Soon Kim ${ }^{1 *}$, Gyung Mee Gim², and Doo Young Ryu ${ }^{3}$ \\ ${ }^{1}$ National Institute of Horticultural \& Herbal Science, RDA, Wanju-gun 55365, Korea \\ ${ }^{2}$ R\&D Performance Evaluation \& Management Division, RDA, Jeonju-si 54875, Korea \\ ${ }^{3}$ Sunchang Agricultural Technology Center, Sunchang-gun 56025, Korea
}

\begin{abstract}
This study was conducted to find out physical changes in the blood pressure and saliva cortisol of patients with high blood pressure and diabetes after participating in agro-healing activities. The saliva cortisol and blood pressure of 14 males and females aged $49.79 \pm 10.48$ on average were measured after participating in agro-healing activities. The saliva collection system was used, and their satisfaction level for the program was also surveyed. Changes in the values before and after participating in the agro-healing activities were compared and analyzed. The cortisol concentration, a stress hormone, was reduced from $6.76 \mathrm{nmol} / \mathrm{L}$ before the program to $4.86 \mathrm{nmol} / \mathrm{L}$ after the program, down by $1.9 \mathrm{nmol} / \mathrm{L}$, which was a statistically significant difference $(z=-3.170, p<.01)$. In addition, the cortisol concentration was gradually reduced through the entire program from Session 1 to Session 7. Changes in the blood pressure of subjects before and after participating in agro-healing activities were examined, and the total systolic and diastolic blood pressure continuously decreased after participating in agro-healing activities through the entire program from Session 1 to Session 7. Their systolic blood pressure was reduced statistically significantly $(z=-1.947, p \chi .05)$. Also, participants' satisfaction was analyzed and it was found that more than $95 \%$ of participants answered 'satisfied' and 'very satisfied' with agro-healing activities. Therefore, these results indicate that agro-healing activities performed in the healing-farm had a positive impact on the cortisol concentration and blood pressure of patients with chronic diseases such as diabetes and high blood pressure. In addition, their high satisfaction for this program seemed to improve the psychological and physiological conditions of subjects.
\end{abstract}

Keywords: care farm, diastolic blood pressure, saliva cortisol system, systolic blood pressure

\section{Introduction}

In modern society, the number of patients with chronic diseases has significantly increased as people's lifestyle changes, and their income increases due to rapid economic growth and population aging. One of the commonly-diagnosed chronic diseases is high blood pressure, and its prevalence rate has topped the list of chronic diseases in South Korea since 1998. It was also reported that $32.7 \%$ of the population aged 30 and over in 2015 had high blood pressure (Korean Centers for Disease Control and Prevention, 2016). Chronic diseases such as high blood pressure and diabetes reduce physical functions, which results in negative emotions such as anxiety, depression and stress, and increases the secretion of cortisol, a major indicator of stress that is secreted under severe stress (Hellhammer et al., 2009). The increasing level of adrenocortical hormone (cortisol) is known to cause metabolic disorders such as

This study was supported by the 2019 Horticultural and Herbal Science Program of the National Institute of Horticultural and Herbal Science of the Rural Development Administration (PJ01137604).

Received: September 11, 2019, Revised: September 19, 2019, Accepted: September 30, 2019

First author: Hye Sook Jang, jhs915@korea.kr, (1) https://orcid.org/0000-0003-3011-8694

*Corresponding author: Jae Soon Kim, kimjs81@korea.kr, (D) https://orcid.org/0000-0002-6529-3225 
high blood pressure, arteriosclerosis and insulin resistance (Vanitallie, 2002). In addition, the adrenocortical hormone increased by stress acts as an anti-insulin hormone, and long-lasting and chronic stress makes the sympathetic nervous system dominant and increases cardiac output, which can increase blood pressure and blood sugar (Björntorp, 2001; Kim et al., 2015; Park and Hwang, 2013; Vickers, 1988). In particular, it is important to keep blood pressure under control in order to prevent chronic renal and vascular complications caused by diabetes (Korean Diabetes Association [KDA], 2019).

However, patients who have to take medicine continuously for controlling blood pressure often forget to take medicine or take medicine wrongly, not following doctors' instructions (Korea Institute for Health and Social Affairs, 2016), which makes it more difficult to control blood pressure. Non-medicinal therapies are also available for patients with chronic diseases such as high blood pressure and diabetes, and, can maximize the effects of medicinal therapies and reduce side effects by improving lifestyle habits and also contributes to reducing the risk of other cardiovascular diseases at the same time (KDA, 2019; The Korean Society of Hypertension, 2018). Complementary and alternative therapies such as acupuncture, mind-body and dietary therapies and naturopathy can be used to maintain and promote the health of patients with chronic diseases based on the natural healing powers of the body (Kim and Kim, 2015).

As the term "healing" has emerged in Korea recently, a number of studies reviewed the effects of agricultural or forest therapy programs for patients with certain diseases, and also confirmed the effects of the therapy programs that are currently operated. Doxon et al. (1987) reported that adults with developmental disorders showed a lower blood pressure in an environment with plants than in an environment without plants. Magnus et al. (1979) also reported that regular light exercises like gardening reduced the number of heart attacks in patients with heart diseases. Another study developed a forest therapy program as an intervention program based on cognitive-behavioral therapy using forest environments and examined its effects on the blood pressure, salivary cortisol and life quality of patients with high blood pressure. The study reported that such programs can be a useful model for controlling high blood pressure considering the significant decrease in the level of cortisol and improvements in their quality of life.

Against this backdrop, this study aimed to assess and verify the effects of agro-healing activities that can reduce stress through active interactions with plants focusing on improving confidence in controlling chronic diseases by themselves by analyzing blood pressure and the concentration of cortisol in saliva, an objective stress indicator.

\section{Research Methods}

\section{Selection of subjects}

To examine the effects of agro-healing activities on the concentration of saliva cortisol and blood pressure of patients with high blood pressure and diabetes, the blood pressure and saliva cortisol (saliva collection system) of a total of 14 adults aged $49.79 \pm 10.5$ before and after participating in agro-healing activities were measured. Subjects were recruited among patents with high blood pressure and diabetes through the online and offline notice boards of Sunchang Agricultural Technology Center. Among the recruited subjects, those who were found to be suitable for this study through a screening test conducted at the Sunchang Health and Longevity Institute were selected. The selected subjects were fully informed of the purpose of this study, the content of agro-healing activities, and items and methods of measurement. The blood pressure and saliva cortisol of those who voluntarily signed the consent form for participation were measured. They were instructed not to drink alcohol for two days before participating in this experiment, and any beverages that might stimulate blood pressure and saliva such as black tea, coffee and green tea for two hours before measuring their physiological signals (Jang et al., 2018, Lee et al., 2009; Park, 2010).

\section{Laboratory conditions and experimental materials and methods}

Physiological signals such as saliva cortisol and blood 
pressure were measured in a space within a healing farm located in Sunchang (Fig. 1). The conditions of the space (length $7.0 \mathrm{~m} \times$ width $6.0 \mathrm{~m} \times$ height $2.6 \mathrm{~m}$ ) were as follows: average illuminance, 700 \pm 10 lux (UT383 Mini Light Meters, Japan); humidity, 70 $\pm 10 \%$ (TR-72Ui, T\&D CORP., Japan); and temperature, $24 \pm 0.5^{\circ} \mathrm{C}$. Agro-healing activities were performed once a week, a total of seven sessions, for 240 minutes ( \pm 10 minutes) per session in indoor and outdoor spaces. Out of the seven sessions, the first (Session 1) and last (Session 7) sessions were operated for two days and one night. Considering the environment of the healing farm and the fact that subjects had chronic diseases, $1 \mathrm{~m} \times 1 \mathrm{~m}$ peanut-shaped vegetable gardens that did not put much stress on their body were created, and the agro-healing program provided in this study was composed of activities of raising vegetables and flowers from sowing and planting seedlings of 10 horticultural plants to harvesting. The activities were designed to utilize the environment and resources of the healing farm, and to improve subjects' sociality and sense of accomplishment and to express themselves through individual and shared activities (Table 1). Their blood pressure was measured and their saliva was collected for phys- iological measurement at the same time before and after participating in each session (Choi et al., 2014; Posener et al., 2000). After the final session, their satisfaction level for the service of the healing farm was surveyed using a 5-point Likert scale. The blood pressure and pulse rate of subjects were measured in a seated position using a portable digital blood pressure monitor (HEM-1000, OMRON, Japan) that uses the oscilloscope method which measures systolic and diastolic blood pressure and pulse rate by monitoring cyclical and repetitive changes in voltage signals over time.

The saliva of subjects was collected using the saliva collection system by instructing them to spit their saliva into a tube. There are various methods for collecting saliva, but the method used in this study is the most convenient one as saliva is directly spitted or drooled into a container (Zava, 2004). However, when saliva is collected by spitting, it is difficult to connect a sufficient amount and quality of saliva, and it can be easily contaminated as it can be contacted with hands or air, which requires special care (Gordon et al., 2005).

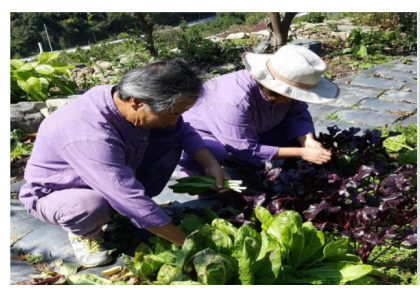

(A)

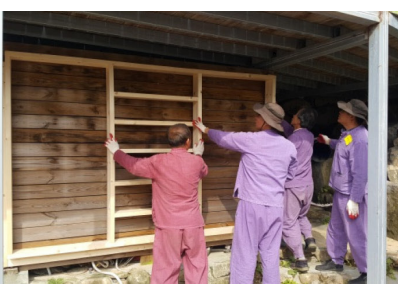

(B)

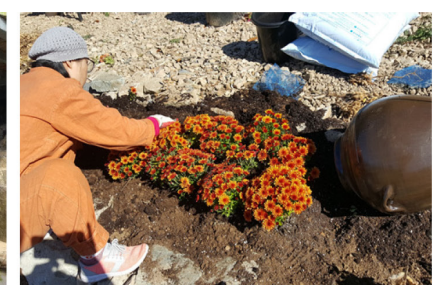

(C)

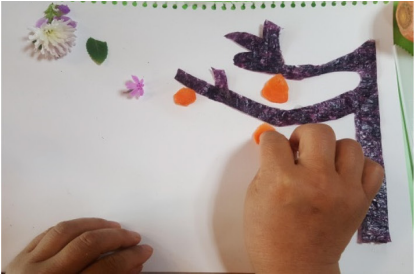

(D)

Fig. 1. Agro-healing activities in healing farm: (A) harvesting vegetables; (B) building a small greenhouse for seedling trays; (C) gardening chrysanthemums; (D) doing food artworks.

Table 1. Agro-healing activities applied to the patients

\begin{tabular}{cl}
\hline Session & \multicolumn{1}{c}{ Agro-healing activity } \\
\hline 1 & $\begin{array}{l}\text { Greetings and education about cultural method of crops, sowing the vegetable seeds, making a small garden, and harvesting } \\
\text { vegetables in healing-farm }\end{array}$ \\
2 & Making a garden name tag and planting seedlings \\
3 & Making a horticultural tool box and small green house for seedling trays \\
4 & Making dried persimmons and making a picture frame with natural materials collected from the farm \\
5 & Designing a chrysanthemum garden and harvesting beans \\
6 & Pruning, harvesting vegetables and taking a walk around care farm \\
7 & Colorful food art and making healthy grain Gangjeong for the patients with metabolic syndrome \\
\hline
\end{tabular}




\section{The content of agro-healing program performed during seven sessions}

The agro-healing program was performed once a week, a total of seven sessions, and was led by the owner of the healing farm who knew the environment and resources of the healing farm well. The developed program was reviewed by an expert of agro-healing programs in advance (Table 1). Criteria for the program and service of the healing farm were set based on the following items: education, healing, social rehabilitation, and improvements in cognitive, socio-psychological and physical functions (Rural Development Administration [RDA], 2017). In addition, the agro-healing program was composed of activities based on the environment of the farm, and the concerns and needs of customers, and it was ensured that participants can experience the activities while interacting with other participants (RDA, 2019). In the first session, participants exchanged greetings and introduced themselves. The owner of the farm provided information on the characteristics of the farm, the overall direction of the program and materials to be used. After that, participants came out to the vegetable garden, mixed soil and sowed Beta vulgaris, Spinacia oleracea, Raphanus sativus var. radicula, Beta vulgaris and Brassica rapa in the trays. A small peanut-shaped vegetable garden was created using natural stones scattered around the farm. After completing these activities in the first session, participants were instructed to write about how they felt during the agro-healing activities on an activity note. In the second session, the seedlings of Lactuca sativa, Brassica campestris, Dendranthema grandiflora and Mentha suaveolens were planted. After that, they made a name plate for their own vegetable garden with wood, and exchanged their thoughts about the reason why they chose the name with others. In the third session, as the outdoor temperature gradually decreased, a mini-sized greenhouse $(30 \mathrm{~cm} \times 55 \mathrm{~cm} \times 12 \mathrm{~cm})$ for the plug trays $(50$ cell) was made with wood. A shared tool box to be used during activities in vegetable gardens was made together, while interacting with others. In the fourth session, tree leaves and autumn flowers were picked from the healing farm, and a frame was made with the natural materials. They had a chance to think about themselves and their family, while decorating the frame with their own instant photos or family photos. In the fifth session, beans were harvested and dried for the activity of making healthy gangjeong with grains good for patients with high blood pressure and diabetes in the seventh session. Dendranthema grandiflora was planted in a streamlined shape like water flowing from a jar. In the sixth session, participants trimmed trees around the farm and talked about the importance of health while strolling around the farm. In the last session, participants made color food artworks using the harvested vegetables and prepared colorful fruits, and during the session they were informed of information on nutrients contained in individual vegetables and fruits by color, the best way to eat them and their efficacy. After making color food artworks, they talked about their motives and feelings, and made gangjeong with grains good for patients with high blood pressure and diabetes.

\section{Satisfaction level of participants for agro-healing program}

The satisfaction level of participants for the agro-healing program was surveyed using a questionnaire composed of 14 questions, and a 5-point Likert scale was used. Those questions have been used to measure the satisfaction level of participants for the services of the healing farm (RDA, 2017). The Cronbach's $\alpha$ value here was .945 .

\section{Statistical analysis}

Statistical analysis in this study was conducted using IBM SPSS Ver. 25.0. The level of cortisol in saliva, blood pressure and satisfaction by session were analyzed using the Wilcoxon paired signed ranks test, and frequency analysis was performed on the satisfaction level for the program of the healing farm and the socio-demographic characteristics of subjects.

\section{Results and Discussion}

\section{General characteristics}

The general characteristics of participants were analyzed, 
and the share of males and females was $64.3 \%$ and $35.7 \%$ respectively. Those in the $50 \mathrm{~s}$ accounted for the largest share $(42.9 \%)$, followed by the 40 s $(28.6 \%), 60$ s and older $(14.3 \%)$, and the $20 \mathrm{~s}$ and $30 \mathrm{~s}$ (7.1\% respectively). In terms of their academic background, the share of college graduates was the highest $(57.2 \%)$, followed by high school graduates $(35.7 \%)$, and graduate school graduates $(7.1 \%)$. In terms of their monthly income, the share of over 4 million won was the highest (28.6\%), followed by $2.51-4$ million won (21.4\%), 1.01-1.5 million won, 2.01-2.5 million won (14.3\%), and 1.51-2 million won (7.1\%) (data not shown).

\section{Changes in the cortisol level of participants after agro-healing activities}

Changes in the level of cortisol before and after participating in agro-healing activities in each session (a total of seven sessions) were analyzed (Table 2), and the overall level of cortisol after participating in agro-healing activities throughout the entire program was lower than the level before participating in the activities. The total average level of cortisol after the program was $4.86 \mathrm{nmol} / \mathrm{L}$, down by $1.90 \mathrm{nmol} / \mathrm{L}(\mathrm{z}=-3.170, p<.01)$ from the level before the program $(6.76 \mathrm{nmol} / \mathrm{L})$, which was a statistically significant difference (Table 2). Compared to other sessions, the level of cortisol after participating in agro-healing activities in the fifth session decreased the most, which indicated that agro-healing activities were effective in reducing the level of cortisol in saliva, a stress hormone. These results were similar to those of the following earlier studies. Jang, Gim et al. (2019) reported that the total concentration of cortisol after participating in community gardening activities including growing plants significantly decreased from the level before participating in the activities. Lee et al. (2013) that provided a horticultural activity program for prisoners to be released reported that the control group did not show any statistically significant difference, but that the experimental group showed a statistically significant decrease in the level of depression and cortisol after participating in the program from the level before participating in the program. Hwang et al. (2007) reported that the level of cortisol of parents of elementary school students who showed high levels of stress was reduced after participating in activities of growing plants, and Jang et al. (2018) also reported that agro-healing activities decreased the level of cortisol in saliva.

\section{Changes in the blood pressure and pulse rate of participants after agro-healing activities}

Changes in the blood pressure of participants before and after participating in agro-healing activities were analyzed, and their systolic blood pressure was reduced by $2.21 \mathrm{mmHg}$ on average from $124.02 \mathrm{mmHg}$ before participating in the activities to $121.82 \mathrm{mmHg}$ after participating in the activities. The diastolic blood pressure was also reduced by $1.19 \mathrm{mmHg}$ on average from $81.13 \mathrm{mmHg}$ to $79.94 \mathrm{mmHg}$. The difference in the systolic blood pressure was statisti-

Table 2. Cortisol level changes among participants between before and after agro-healing activities

\begin{tabular}{|c|c|c|c|c|c|}
\hline \multirow{2}{*}{ Session } & \multicolumn{2}{|c|}{ Cortisol level (nmol/L) } & \multirow{2}{*}{ Before - after } & \multirow{2}{*}{$z$} & \multirow[b]{2}{*}{$p$} \\
\hline & Before & After & & & \\
\hline 1 & $5.490 \pm 1.10^{z}$ & $4.740 \pm 0.93$ & 0.850 & -0.948 & $.343^{\mathrm{NS}}$ \\
\hline 2 & $6.800 \pm 1.10$ & $6.020 \pm 1.34$ & 0.780 & -0.866 & $.386^{\mathrm{NS}}$ \\
\hline 3 & $5.658 \pm 0.96$ & $4.733 \pm 1.09$ & 0.925 & -1.413 & $.158^{\mathrm{NS}}$ \\
\hline 4 & $8.030 \pm 1.03$ & $5.820 \pm 0.73$ & 2.210 & -2.666 & $.008^{* *}$ \\
\hline 5 & $7.850 \pm 1.07$ & $4.450 \pm 0.76$ & 3.400 & -2.524 & $.012 *$ \\
\hline 6 & $7.792 \pm 1.75$ & $4.492 \pm 0.63$ & 3.300 & -2.314 & $.021^{*}$ \\
\hline 7 & $5.091 \pm 0.84$ & $4.550 \pm 1.20$ & 0.536 & -0.979 & $.328^{\mathrm{NS}}$ \\
\hline Total & $6.760 \pm 0.87$ & $4.860 \pm 0.60$ & 1.900 & -3.170 & $.002 * *$ \\
\hline
\end{tabular}

${ }^{\mathrm{z}}$ Values are mean \pm standard error.

${ }^{\mathrm{NS}}$ Non-significant, ${ }^{*} p<.05,{ }^{* *} p<.01$ by Wilcoxon Paired Signed Ranks Test $(\mathrm{N}=14)$. 
Table 3. Blood pressure changes among participants between before and after agro-healing activities

\begin{tabular}{lcccc}
\hline \multicolumn{1}{c}{ Blood pressure } & Before & After & $z$ & $p$ \\
\hline Systolic blood pressure & $124.02 \pm 3.67^{\mathrm{z}}$ & $121.82 \pm 3.57$ & -1.947 & $.050^{*}$ \\
Diastolic blood pressure & $81.13 \pm 2.76$ & $79.94 \pm 2.57$ & -1.572 & $.116^{\text {NS }}$ \\
Total & $71.27 \pm 1.52$ & $71.11 \pm 1.85$ & -0.175 & $.861^{\text {NS }}$ \\
\hline
\end{tabular}

${ }^{\mathrm{z}}$ Values are mean \pm standard deviation.

${ }^{\mathrm{NS}}$ Non-significant, ${ }^{*} p<.05$ by Wilcoxon Paired Signed Ranks Test $(\mathrm{N}=14)$.

Table 4. Percent of participants by satisfaction for each session in agro-healing program

\begin{tabular}{cccccc}
\hline Session & Very dissatisfied & Dissatisfied & Neither & Satisfied & Very satisfied \\
\hline 1 & 0.0 & 0.0 & 0.0 & 60.7 & 39.3 \\
2 & 0.0 & 0.0 & 0.0 & 55.6 & 44.4 \\
3 & 0.0 & 0.0 & 8.3 & 58.4 & 33.3 \\
4 & 0.0 & 0.0 & 0.0 & 70.0 & 30.0 \\
5 & 0.0 & 0.0 & 0.0 & 57.1 & 42.9 \\
6 & 0.0 & 0.0 & 0.0 & 50.0 & 50.0 \\
7 & 0.0 & 0.0 & 0.0 & 33.3 & 66.7 \\
\hline
\end{tabular}

Note. 5-point Likert scale was used for the survey $(\mathrm{N}=14)$.

cally significant, but that in the diastolic blood pressure was not statistically significant. For patients with chronic diseases including high blood pressure and diabetes, the level of blood pressure is very important. The statistically significant decrease in the systolic blood pressure of participants after participating in agro-healing activities indicates that agro-healing activities were effective in reducing blood pressure (Table 3). There are several studies that support the results of this study. Sung et al. (2011) reported that the blood pressure of patients with senile high blood pressure significant decreased after participating in a forest therapy program, and Ochiai et al. (2015) also reported that the blood pressure of middle-aged men who had high blood pressure decreased to the optimal level after participating in forest therapy activities. Another study on the effects of walking in forests on the activity of the autonomic nervous system of middle-aged people reported that strolling in a natural environment, compared to strolling in an urban environment, was effective in relaxing the physiological and psychological conditions of middle-aged patients with high blood pressure (Song et al., 2015). Although programs used in these studies were different from the agro-healing activities used in this study, they still support this study considering that the results were obtained through activities or works that involve nature.

\section{Satisfaction of participants for the agro-healing activities of each session}

The satisfaction level of participants for the agro-healing activities of each session was surveyed, and those who answered "satisfied" and "very satisfied" accounted for over $98 \%$. As the owner of the farm who knew the characteristics and environment of the farm well led the program, participants seemed to be highly satisfied with the program (Table 4).

\section{Satisfaction of participants for the service of the healing farm after agro-healing activities}

The satisfaction level of participants for the service of the healing farm was surveyed after the last session (Table 5), and $100 \%$ of the participants answered that they were satisfied with the service to Question No. 3 "Problems raised by participants were checked and addressed sincerely," and Question No. 13 "Services that I wanted were provided." To Question No. 11 "Staff members were well 
Table 5. Percent of participants by service satisfaction in agro-healing program

\begin{tabular}{cccccc}
\hline Item & Very dissatisfied & Dissatisfied & Neither & Satisfied & Very satisfied \\
\hline $1^{\mathrm{z}}$ & 0.0 & 0.0 & 7.1 & 50.0 & 42.9 \\
2 & 0.0 & 0.0 & 21.4 & 42.9 & 35.7 \\
3 & 0.0 & 0.0 & 0.0 & 50.0 & 50.0 \\
4 & 0.0 & 0.0 & 0.0 & 42.9 & 57.1 \\
5 & 0.0 & 0.0 & 7.7 & 61.5 & 30.8 \\
6 & 0.0 & 0.0 & 0.0 & 35.7 & 64.3 \\
7 & 0.0 & 0.0 & 0.0 & 42.9 & 57.1 \\
8 & 0.0 & 0.0 & 0.0 & 35.7 & 64.3 \\
9 & 0.0 & 0.0 & 7.2 & 35.7 & 57.1 \\
10 & 0.0 & 0.0 & 0.0 & 28.6 & 71.4 \\
11 & 0.0 & 0.0 & 14.2 & 42.9 & 42.9 \\
12 & 0.0 & 0.0 & 0.0 & 35.7 & 64.3 \\
13 & 0.0 & 0.0 & 0.0 & 50.0 & 50.0 \\
14 & 0.0 & 0.0 & Satisfaction Cronbach's $\alpha=.945$ & 42.9 & 42.9 \\
\hline
\end{tabular}

Note. 5-point Likert scale was used for the survey $(\mathrm{N}=14)$.

${ }^{\mathrm{z}}$ Service satisfaction item; 1 =facilities are convenient and attractive; $2=$ signs or information on the service of the healing farm were provided well; $3=$ problems raised by participants were checked and addressed sincerely; $4=$ healing farm and it's staffs fulfill the contracts well; $5=$ service records, charges and other items are in care farm provided correctly; $6=$ staffs are willing to help the customer; $7=$ staffs respond quickly to the customer's demands; $8=$ staffs are trustworthy; $9=$ care farm's services are stable and relaxed; $10=$ staffs are courteous to customers; $11=$ staffs are well aware of the customer's needs; $12=$ care farms try to protect customers' interests; $13=$ services that I wanted were provided; $14=$ service of this healing farm met my needs.

aware of customers' needs and treated individuals with respect" and Question No. 14 "The service of this healing farm met my needs" participants showed $86 \%$ of satisfaction. To Question No. 2 "Signs or information on the service of the healing farm were provided well" participants showed the lowest satisfaction level (78\%). These results indicate that the owner and staff members of the healing farm made earnest efforts to treat participants sincerely, but that they seemed to be unskilled in terms of safety, the most important aspect. Since tools are used in many activities and participants are not well aware of directions of movement and facilities, it seems to be important to place more sings on safety and facilities.

\section{Conclusion}

To examine changes in the concentration of saliva cortisol and blood pressure of patients with high blood pressure and diabetes after participating in agro-healing activities, this study measured the saliva cortisol and blood pressure of a total of 14 adults (aged 49.79 \pm 10.48 ) who participated in the agro-healing program developed in this study, and surveyed their satisfaction level for the program. Their cortisol level and blood pressure before and after participating in the activities of the agro-healing program were compared and analyzed, and the average concentration of cortisol, a stress hormone, from $6.76 \mathrm{nmol} / \mathrm{L}$ before participating in the activities to $4.86 \mathrm{nmol} / \mathrm{L}$ after participating in the activities, down by $1.9 \mathrm{nmol} / \mathrm{L}(\mathrm{z}=-3.170, p<.01)$, which was a statistically significant difference. In addition, the concentration of cortisol tended to continuously decrease throughout the entire program from Session 1 to 7 . Jang et al. (2018) reported that the level of cortisol of parents was reduced after participating in activities of growing plants. Changes in the blood pressure of participants after participating in the agro-healing activities were also examined, and the systolic and diastolic blood pressure of participants 
after participating in the agro-healing activities throughout the entire program tended to decrease, and their systolic blood pressure showed a statistically significant difference $(\mathrm{z}=-1.947, p<.05)$. The satisfaction level of participants for the agro-healing program was also surveyed, and, out of a total of 14 questions, over $90 \%$ of the surveyed participants answered to four questions that they were satisfied with the services of the healing farm. In addition, the overall satisfaction level of participants for the ago-healing program was also analyzed, and over $95 \%$ of the surveyed participants answered that they were "satisfied" and "very satisfied," which indicates that their satisfaction level for individual sessions was very high. These results demonstrate that the agro-healing program in healing farms or visual elements such as the landscape of the healing farm are effective in reducing the concentration of cortisol, a stress hormone, and blood pressure of patients with metabolic chronic diseases such as high blood pressure and diabetes. In addition, the high satisfaction level of participants for the program of the healing farm also indicates that the program had a positive impact on their mental and physiological health. Physical activities using horticultural plants such as plowing soil, sowing, watering plants and removing weeds (Matsuo and Miyajima, 1998), and the visual elements of healing farms were reported to be effective for brain activities, relaxation and stability under no stress or tension (Jang, You et al., 2019; Kim et al., 2002; Son et al., 1998, 1999). For this reason, it is urgently needed to develop agro-healing programs customized for certain targets such as patients with high blood pressure or diabetes (Lee et al., 2011). Meanwhile, there were some limitations in this study. Since the program was provided once a week, it was difficult to control other factors that might affect the effect of agro-healing activities such as living environments and background variables. As a certain group of people, here patients with high blood pressure and diabetes, was targeted in this study, the representativeness of samples was not fully reflected in the process of sampling, which makes it difficult to generalize the results of this study. To address these limitations, it will be necessary to standardize agro-healing programs by conducting follow-up studies continuously.

\section{References}

Björntorp, P. 2001. Do stress reactions cause abdominal obesity and comorbidities? Obes. Rev. 2(2):73-86.

Choi, S.H., I.S. See, I.J. Song, O.J. Kwon, K.O. Park, H.J. Hong, K.K. Sung, and S.K. Lee. 2014. Method of saliva collection for salivary cortisol measurement. Korean J. Orient. Physiol. Pathol. 28(2):223-232. http s://doi.org/10.15188/kjopp.2014.04.28.2.223

Doxon, L.E., R.H. Mattson, and A.P. Jurich. 1987. Human stress reduction through horticultural vocational training. HortScience 22(4):655-656.

Gordon, M.K., E. Peloso, A. Auker, and M. Dozier. 2005. Effect of flavored beverage crystals on salivary cortisol enzyme-immunoreactive assay measurements. Dev. Ps ychobiol. 47(2):189-195. https://doi.org/10.1002/dev.2 0081

Hellhammer, D.H., S. Wüst, and B.M. Kudielka. 2009. Salivary cortisol as a biomarker in stress research. Psychoneuroendocrinology 34(2):163-171. https://doi.org/10.1016/j.psyneuen.2008.10.026

Hwang, H.J., Y.A. Lee, J.E. Song, and K.C. Son. 2007. Effect of horticultural therapy based upon reality therapy on the reduction of depression, the change in parental sense of competence, and stress coping types of elementary student's mother. Korean J. Hortic. Sci. Technol. 25(3):268-276.

Jang, H.S., E.H. Yoo, S.J. Jeong, J.S. Kim, and D.Y. Ryu. 2019. Effects of an agro-healing activity program on the physiological condition of adults with chronic metabolic diseases. J. People Plants Environ. 22(4):355-364. https://doi.org/10.11628/ksppe.2019.22.4.355

Jang, H.S., G.M. Gim, S.J. Jeong, and J.S. Kim. 2018. Effects of plant cultivating activity for reducing parental stress. J. People Plants Environ. 21(3):203-211. https://doi.org/10.11628/ksppe.2018.21.3.203

Jang, H.S., G.M. Gim, S.J. Jeong, and J.S. Kim. 2019. Community gardening activities and their effects on mental health of residents. J. People Plants Environ. 22(4):333-340. https://doi.org/10.11628/ksppe.2019.2 2.4 .333

Kim, E.I., S.H. Hwang, W.S. Shin, and K.W. Ahn. 2002. 
Physiological effect of forest types: Focused on brain wave and pulsation. J. Korean Inst. For. Recreat. 6(2):43-48

Kim, H.J., J.Y. Jun, and G.S. Song. 2015. The literature review of intervention program with hypertension. J. Korea Soc. Wellness 10(3):197-212.

Kim, J.C. and P.H. Kim. 2015. Perception level of complementary and alternative therapy and its related factors among geriatrics hospital employees. J. Korea Soc. Wellness 10(4):95-104.

Korea Centers for Disease Control and Prevention. 2016. The sixth Korea national health and nutrition examination survey (KNHANES VI-3). Cheongju, Korea: Author. Retrieved from www.cdc.go.kr

Korea Institute for Health and Social Affairs. 2016. Analysis and improvement of medical use for chronic diseases: Around high blood pressure and diabetes. Sejong, Korea: Author. Retrieved from www.kihasa.re.kr

Korean Diabetes Association. 2019. Treatment guideline for diabetes. Seoul, Korea: Author.

Lee, E.D., S.J. Park, R.H. Yoo, and S.J. Hong. 2011. Analysis on the activity contents of forest healing programs in Korea. J. Korean Inst. For. Recreat. 15(2): 101-109.

Lee, J.H., W.S. Shin, P.S. Yeoun, and R.H. Yoo. 2009. The influence of forest scenes on psychophysiological responses. J. Korean For. Soc. 98(1):88-93.

Lee, S.M., J.H. Moon, S.J. Jeong, and Y.J. Lee. 2013. Effects of horticultural therapy program focusing on cultivating activities for prisoners scheduled to be released on depression and salivary cortisol. J. Korean Soc. People Plants Environ. 16(4):173-180. https://doi.org/10.11628/ksppe.2013.16.4.173

Magnus, K., A. Matroos, and J. Strackee. 1979. Walking, cycling, or gardening, with or without seasonal interruption, relation to acute coronary events. Am. J. Epidemiol. 110(6):724-733.

Matsuo, E. and I. Miyajima. 1998. Up-to-date trend of horticultural therapy in Japan: An attempt to redefine horticulture in horticultural therapy and place horticultural therapy in relation to other therapies. J. Korean. soc. People Plants Environ 1(1):22-33.
Ochiai, H., H. Ikei, C.R. Song, M. Kobayashi, A. Takamatsu, T. Miura, T. Kagawa, Q. Li, S. Kumeda, M. Imai, and Y. Miyazaki. 2015. Physiological and psychological effects of forest therapy on middle-aged males with high-normal blood pressure. Int. J. Environ. Res. Public Health 12(3):2532-2542. https://doi.org/10.3390/ijerph 120302532

Park, B.J. 2010. Experimental approach of therapeutic effect of forest recreation activities: Focused on viewing and walking in forest environments. Doctoral dissertation, Chungnam National University, Daejeon, Korea.

Park, S.H. and B.D. Hwang. 2013. The effect of their sense of depression and suicidal thinking for managerial characteristics in hypertense and diabetic patients. Korean J. Health Serv. Manag. 7(4):221-232.

Posener, J.A., C. DeBattista, G.H. Williams, H.C. Kraemer, B.M. Kalehzan, and A.F. Schatzberg. 2000. 24-hour monitoring of cortisol and corticotropin secretion in psychotic and nonpsychotic major depression. Arch. Gen. Psychiatry 57(8):755-760.

Rural Development Administration. 2017. Technology dissemination manual of preventative oriented type agro-healing. Wanju, Korea: Author.

Rural Development Administration. 2019. Regional agro healing agriculture practice manual: focusing on collaborative cases of family and healthcare care farm. Wanju, Korea: Aurhor.

Son, K.C., J.S. Lee, and J.E. Song. 1998. Effect of visual recognition of indoor plants on changes of human brain electroencephalography. J. Korean Soc. Hortic. Sci. 39(6):858-862.

Son, K.C., J.S. Lee, and J.E. Song. 1999. Effect of visual recognition of Ficus benjamina and its photograph on changes of human brain electroencephalography and brain blood flow. J. Korean Soc. Hortic. Sci. 40(1): 134-138.

Song, C.R., H. Ikei, M. Kobayashi, T. Miura, M. Taue, T. Kagawa, Q. Li, S. Kumeda, M. Imai, and Y. Miyazaki. 2015. Effect of forest walking on autonomic nervous system activity in middle-aged hypertensive individuals: A pilot study. Int. J. Environ. Res. Public Health 12(3): 2687-2699. https://doi.org/10.3390/ijerph120302687 
Sung, J.D., J.M. Woo, W. Kim, S.K. Lim, and E.J. Chung. 2011. The effect of cognitive behavior thera: Based "forest therapy" program on blood pressure, salivary cortisol level, and quality of life in elderly hypertensive patients. Clin. Exp. Hypertens. 34(1):1-7. https://doi.or $\mathrm{g} / 10.3109 / 10641963.2011 .618195$

The Korean Society of Hypertension. 2018. Hypertension diagnosis guideline. Seoul, Korea: Author.

Vanitallie, T.B. 2002. Stress: A risk factor for serious illness. Metabolism 51(6 Suppl 1):40-45. https://doi.or g/10.1053/meta.2002.33191

Vickers, R.R., Jr. 1988. Effectiveness of defenses: A significant predictor of cortisol excretion under stress. J. Psychosom. Res. 32(1):21-29. https://doi.org/10.101 6/0022-3999(88)90085-2

Zava, D. 2004, January. Saliva hormone testing. Townsend Letter for Doctors \& Patients, 120-124. 